NASA

Technical

Paper

3431

March 1994
Structurally Compliant Rocket Engine

Combustion Chamber-Experimental and Analytical Validation
Robert S. Jankovsky, Vinod K. Arya,

John M. Kazaroff, and Gary R. Halford 


\section{NASA \\ Technical \\ Paper \\ 3431}

1994

Structurally Compliant Rocket Engine

Combustion Chamber-Experimental

and Analytical Validation

Robert S. Jankovsky

Lewis Research Center

Cleveland, Ohio

Vinod K. Arya

University of Toledo

Toledo, Ohio

John M. Kazaroff and Gary R. Halford

Lewis Research Center

Cleveland, Ohio

National Aeronautics and Space Administration

Office of Management

Scientific and Technical Information Program 


\title{
Structurally Compliant Rocket Engine Combustion Chamber- Experimental and Analytical Validation
}

\author{
Robert S. Jankovsky \\ NASA Lewis Research Center \\ Cleveland, Ohio 44135 \\ Vinod K. Arya \\ University of Toledo \\ Toledo, Ohio 43606 \\ John M. Kazaroff and Gary R. Halford \\ NASA Lewis Research Center \\ Cleveland, Ohio 44135
}

\section{Summary}

A new, structurally compliant rocket engine combustion chamber design has been validated through analysis and experiment. Subscale, tubular channel chambers have been cyclically tested and analytically evaluated. Cyclic lives were determined to have a potential for 1000 percent increase over those of rectangular channel designs, the current state of the art. Greater structural compliance in the circumferential direction gave rise to lower thermal strains during hot firing, resulting in lower thermal strain ratcheting and longer predicted fatigue lives. Thermal, structural, and durability analyses of the combustion chamber design, involving cyclic temperatures, strains, and low-cycle fatigue lives, have corroborated the experimental observations.

\section{Introduction}

Rocket combustion chambers, such as the one used in the space shuttle main engine, operate at extremely high heat flux (100 Btu/in. ${ }^{2}$-sec at the throat). The high heat flux results from high-temperature $\left(3315^{\circ} \mathrm{C} ; 6000^{\circ} \mathrm{F}\right)$, high-pressure (20 MPa; $3000 \mathrm{psi}$ ) combustion gases. Active cooling of the chamber is mandatory to keep the hot-gas-side wall material from melting. The choice of materials for constructing the hot-gas-side wall is limited. Only materials with extremely high thermal conductivity can survive in these severe environments without melting or otherwise losing their structural integrity. Copper and dilute copper-base alloys offer the highest possible thermal conductivity with mechanical properties sufficient to withstand static and cyclic loading.

Mechanical durability of copper chambers can be limited by several potential failure modes: creep-rupture, low-cycle thermal fatigue, and thermal-mechanical ratcheting. The useful life of the throat region of the space shuttle main engine, a rectangular channel chamber, is governed by thermal-mechanical ratcheting. Ratcheting takes the form of local bulging and thinning of the rectangular channel wall separating the hot-gas and coolant sides, as indicated by the "doghouse" configuration in figure 1 (from ref. 1). The rate of ratcheting and wall thinning is a strong function of the severity of thermal loading (both maximum temperature and thermal gradients), the thermal and structural compliance, and the geometry of the combustion chamber and is a lesser function of the material strength and ductility. Elimination of the ratcheting failure mode by improving material strength and ductility is highly unlikely because extremely large increases in material properties are required. Only incremental improvements in material properties are feasible at this time. However, as seen from the results of the current experimental and analytical study, significant improvements can be made in the geometry of the cooling channels, and these considerably reduce the amount of ratcheting and thereby extend life. Unfortunately, the type of failure expected, thermal-mechanical ratcheting, cannot be analytically modeled within the present state of the art. Both thermalmechanical ratcheting and fatigue are strainrange dominated; therefore, it is reasonable to infer that a fatigue analysis would provide a fair estimate of the relative lives of channel geometries.

In this study the structural durabilities of a tubular channel chamber (fig. 2) and a rectangular channel chamber were compared. Experimentally, subscale hardware was designed and tested to isolate the effects of geometry on thrust chamber life. The experimental hardware was analytically modeled. A new viscoplastic, constitutive stress-strain model for copper was incorporated into the chamber models, and the two configurations were compared at nominal operating conditions. The experimental results from subscale chamber testing confirmed the expectations of the analyses, that significant improvements in cyclic durability can be expected from more compliant, less constrained channel constructions. 


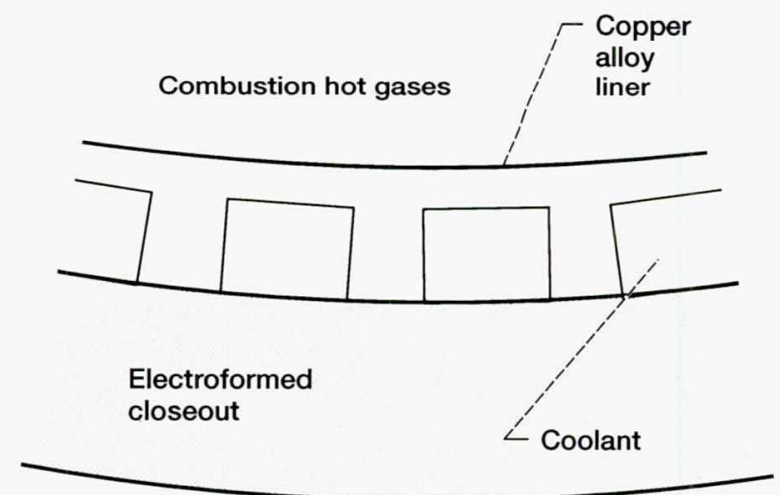

(a)

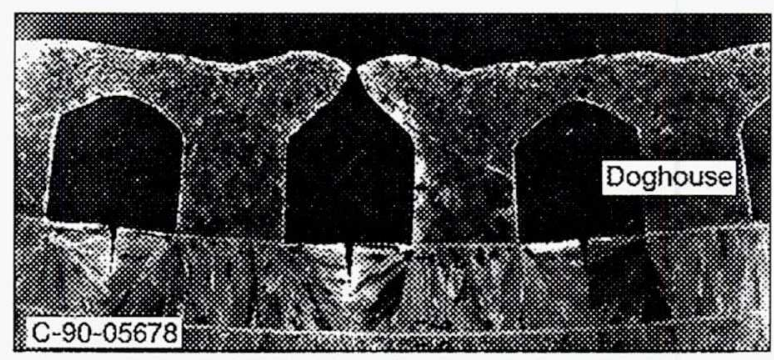

(b)

Figure 1.-Milled rectangular channels. (a) Before repeated firings. (b) After repeated firings.

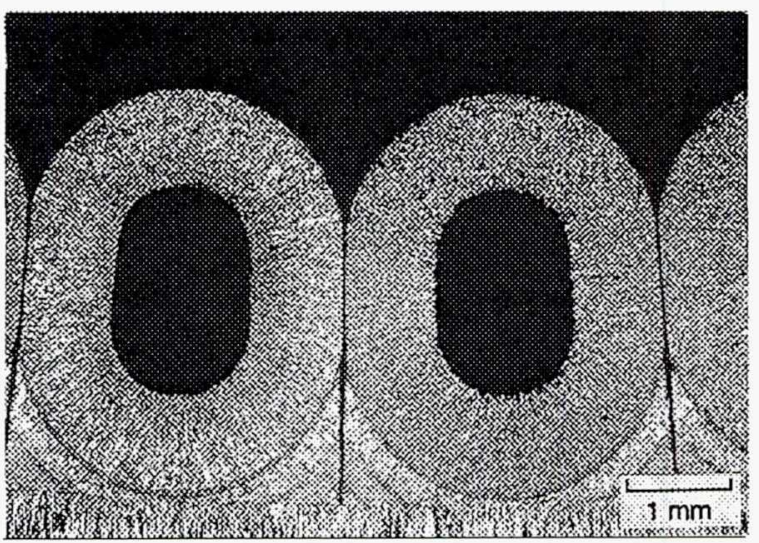

Figure 2.-"Booked" tubular channel construction.

\section{Experimental Investigation}

The testing of both chamber designs has been previously reported. The rectangular channel testing is reported in reference 1 , and the tubular channel testing is reported in reference 2 . The apparatus, test procedure, and results are summarized here.

\section{Apparatus}

A broad base of data on copper-alloy combustion chambers with rectangular channel coolant passages has been obtained on a low-cost, subscale rocket engine test apparatus at NASA Lewis Research Center. The apparatus is used to study the cyclic durability of rocket chamber walls, to screen candidate chamber-wall materials, and to evaluate fabrication techniques for improved life and performance. The test apparatus, shown in figure 3 , consists of an annular injector; a 15.24-cm (6.0-in.) long, liquid-hydrogen-cooled outer cylinder, which serves as the test chamber; and a water-cooled centerbody, which forms the combustion, sonic throat, and expansion sections of an annular rocket engine. It is at the sonic throat station that the maximum heat flux is encountered, and this is the location that is studied for fatigue. The standard test chamber configuration has 72 rectangular coolant passages (ref. 1).

A variation of this standard configuration was used for the comparison reported herein. A new test chamber was designed with a stacked bundle of 72 oxygen-free, high-conductivity (OFHC) copper tubes as the coolant passages, as shown in figure 4. The same number of coolant passages is used in the standard rectangular channel chambers, thus allowing direct comparison of results. To provide a coolant flow area equivalent to the rectangular channel configuration and to maintain the same wall thickness, round tubes were required to be "booked" (i.e., compressed to form the oval shape shown in figure 5).

\section{Procedure}

The test procedure for the tubular channel chambers was identical to that used for fatigue tests of the rectangular channel chambers described in reference 1. Gaseous hydrogen and liquid oxygen were used as propellants at a nominal mixture ratio of 6.0 at a chamber pressure of $4137 \mathrm{kPa}$ ( $600 \mathrm{psia})$. The maximum hot-gas-side wall temperature was controlled by a separate mass flow of liquid hydrogen through the coolant passages. The chamber was fired for $1.7 \mathrm{sec}$ to allow it to reach thermal equilibrium and then shut down for $1.8 \mathrm{sec}$ while the coolant continued to flow to achieve steady-state cold conditions. The total cycle time was $3.5 \mathrm{sec}$, as shown in figure 6 . This cycle was repeated approximately 50 times. The combustion chamber was then inspected and subjected to another 50 cycles. This sequence was repeated until a combustion chamber failure was detected by sensing a coolant passage leak.

\section{Results}

Two tubular channel chambers were tested for comparison with the rectangular channel chambers of reference 1 . The first chamber was test fired at the nominal combustion conditions and a hot-gas-side wall temperature of $570{ }^{\circ} \mathrm{C}\left(1060{ }^{\circ} \mathrm{F}\right)$. Failure occurred after 637 cycles. The second chamber was 


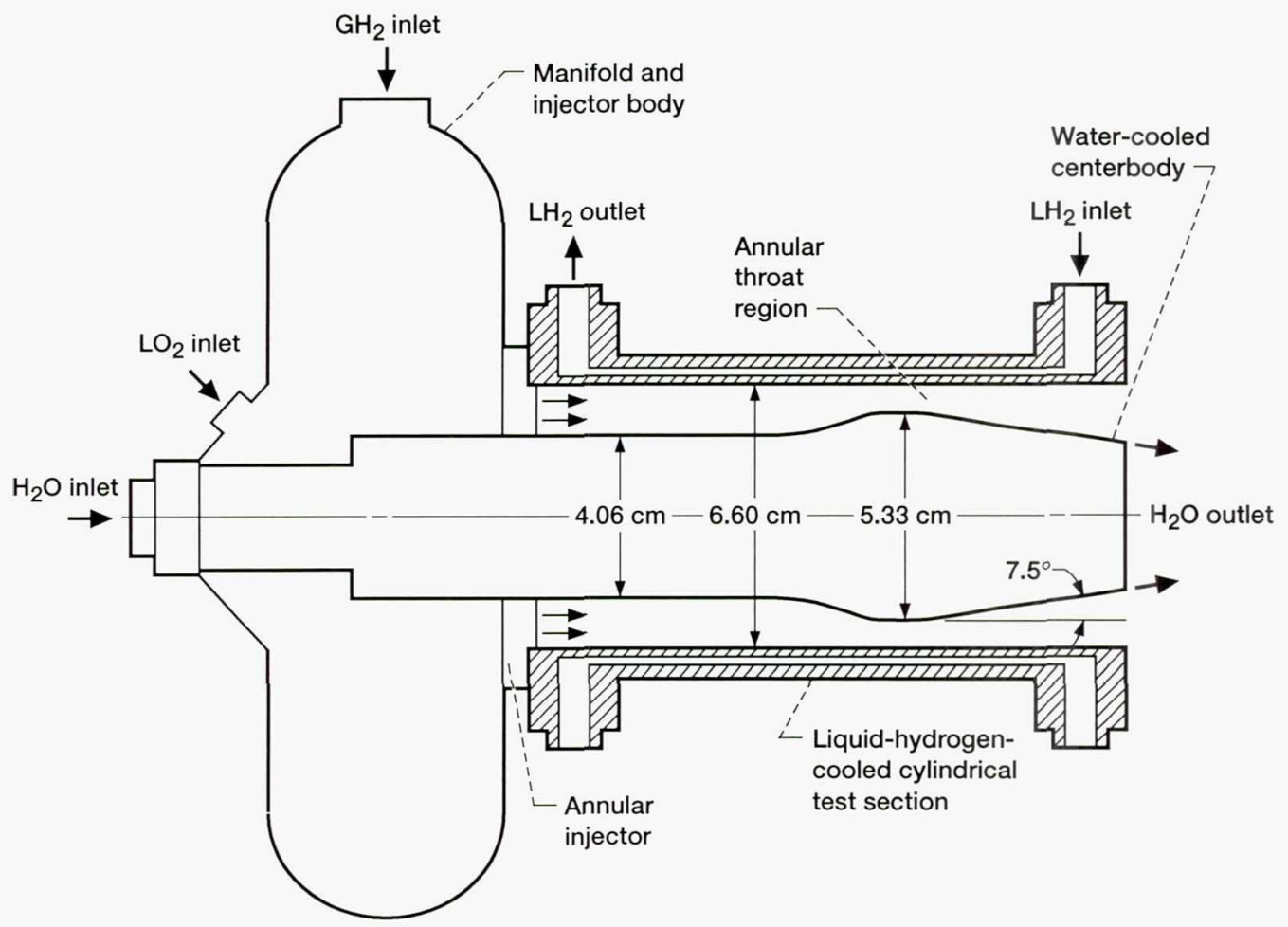

Figure 3.-Subscale rocket engine test apparatus.

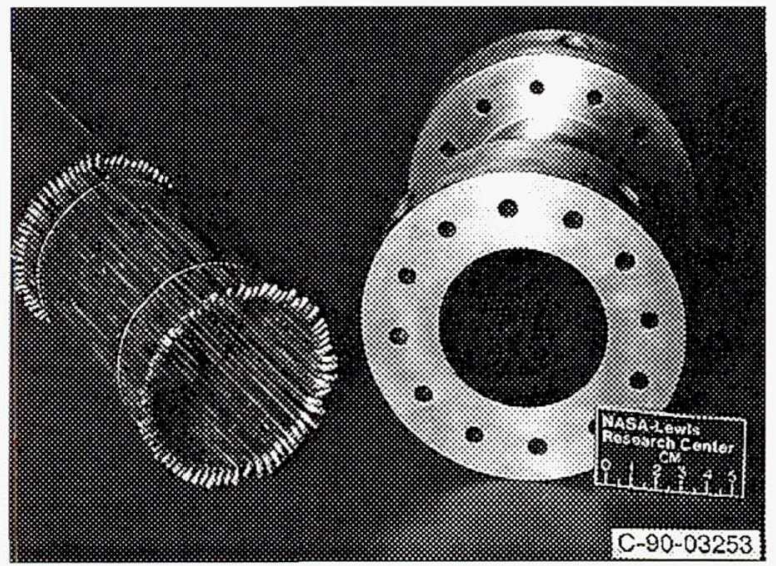

Figure 4.-Stack of OFHC copper tubes and completed subscale thrust chamber.

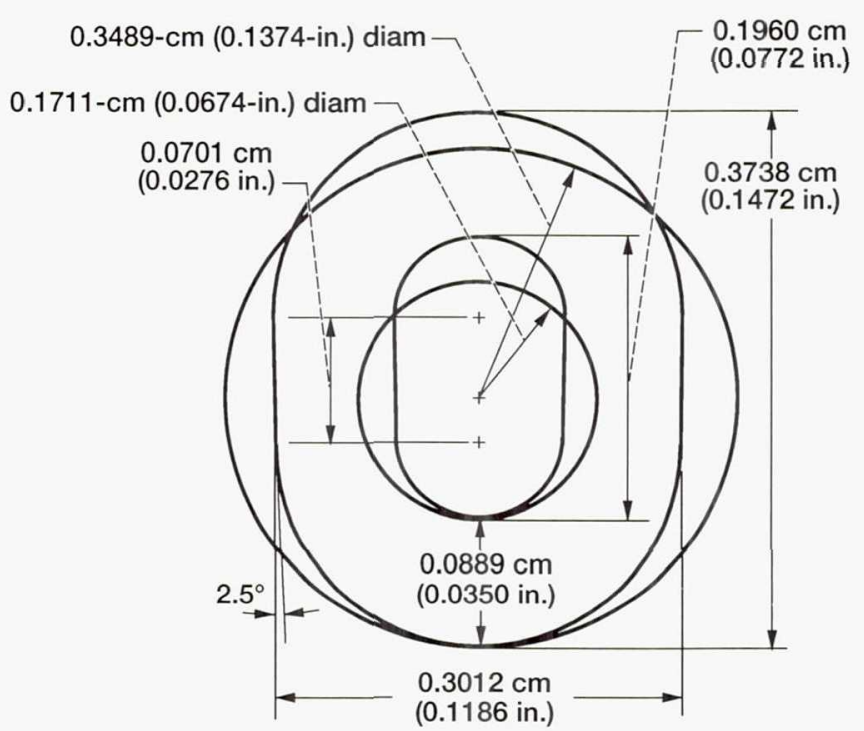

Figure 5.-Diagram of tube dimensions (round to booked). also test fired at nominal combustion conditions but was run with a hot-gas-side wall temperature of $671^{\circ} \mathrm{C}\left(1240^{\circ} \mathrm{F}\right)$. This chamber failed after 256 cycles (ref. 2).

Rectangular channel chambers were tested at the same nominal operating conditions as the tubular chambers and at a wide range of hot-gas-side wall temperatures (ref. 1). The number of cycles to failure expected for a rectangular channel chamber of this configuration tested at $538{ }^{\circ} \mathrm{C}\left(1000{ }^{\circ} \mathrm{F}\right)$ is 250 cycles and 117 cycles for one tested at $671^{\circ} \mathrm{C}\left(1240{ }^{\circ} \mathrm{F}\right)$ (ref. 1). Comparing the test fire results for the two types of chambers shows two to three times more cycles to failure for the tubular chamber. 


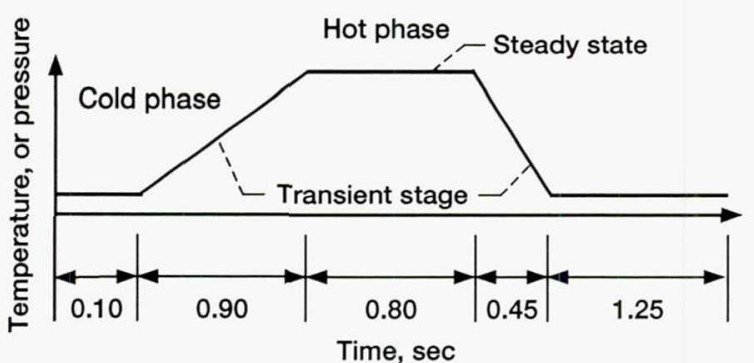

Figure 6.-Schematic cycle of loading (typical cycle history).

\section{Analytical Investigation}

\section{Finite Element Thermal and Structural Analyses}

Accurate predictions of the cyclic lives of the tubular and rectangular channels require accurate assessments of the inelastic response of these channels. Advanced viscoplastic models treat all the inelastic strains (including creep, plastic, relaxation, etc.) as a single entity and thus automatically include any interactions among them. Viscoplastic models, therefore, provide realistic descriptions of inelastic response. In this study a viscoplastic model put forth by Freed and Verrilli (ref. 3) was employed to calculate the inelastic response of the channels. This viscoplastic model is described briefly in the appendix. The material constants for copper for this model are given in table I.

The constitutive equations of the viscoplastic model are highly nonlinear and mathematically "stiff." Applying viscoplastic models to structural engineering problems, such as the present channel comparison problem, requires the development of suitable numerical solution technologies employing, for example, the finite element method. In the present work a numerical solution technology put forth by Arya and Kaufman (ref. 4) was employed. The general-purpose finite element program MARC (ref. 5) was used to perform the finite element calculations. Time integration of the stiff constitutive equations

TABLE I.-MATERIAL CONSTANTS FOR COPPER [From reference 3.]

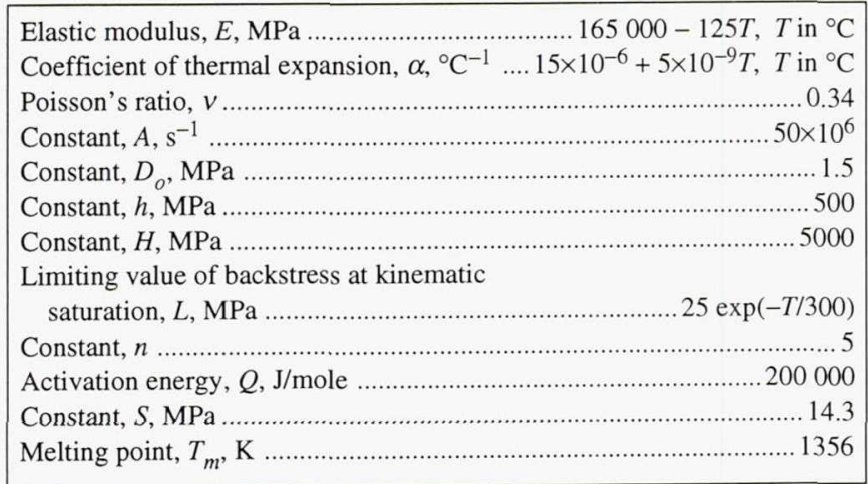

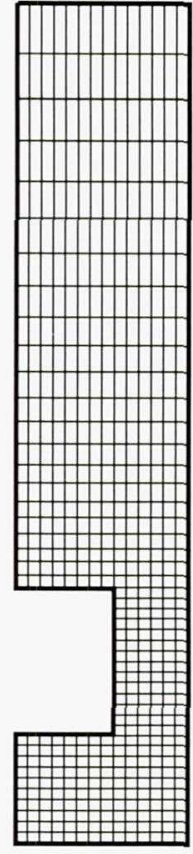

532 Elements, 601 nodes

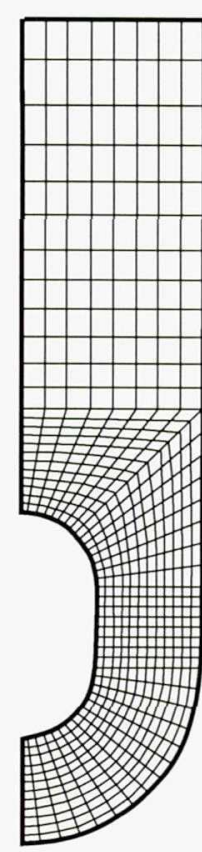

552 Elements 615 nodes
Figure 7.-Finite element models of rectangular and tubular channels.

of the viscoplastic model requires efficient and accurate integration techniques. Because the use of an explicit integration method does not require the assembly and inversion of Jacobian matrices, a time integration strategy, developed by Arya et al. (ref. 6) and based on the explicit forward Euler method, was employed here. This integration strategy has been successfully applied to numerous problems and has been found to work well for problems that involve complex thermal and/or mechanical loadings (refs. 7 and 8 ).

The finite element models for the rectangular and tubular channels were generated by using the PATRAN program (ref. 9). These models are shown in figure 7. Generalized plane strain, isoparametric elements were used to model the smallest repeating segment of the chamber walls. The use of these elements facilitated quasi-three-dimensional analyses for the channels. The rectangular channel model consisted of 532 elements and 601 nodes, whereas the tubular channel model was constructed with 552 elements and 615 nodes. These finite element models were used to perform the thermal and structural analyses presented here.

Steady-state heat transfer analyses were performed to obtain the temperature profiles for the rectangular and tubular channels. Relevant properties and boundary conditions were input to the MARC program. The steady-state temperature distributions for the rectangular and tubular channels obtained from these analyses, shown in figure 8, were akin to each other.

The cyclic thermal and mechanical loadings used in the finite element analyses are shown in figure 6 and table II (also see 
Temperature,

${ }^{\circ} \mathrm{C}$
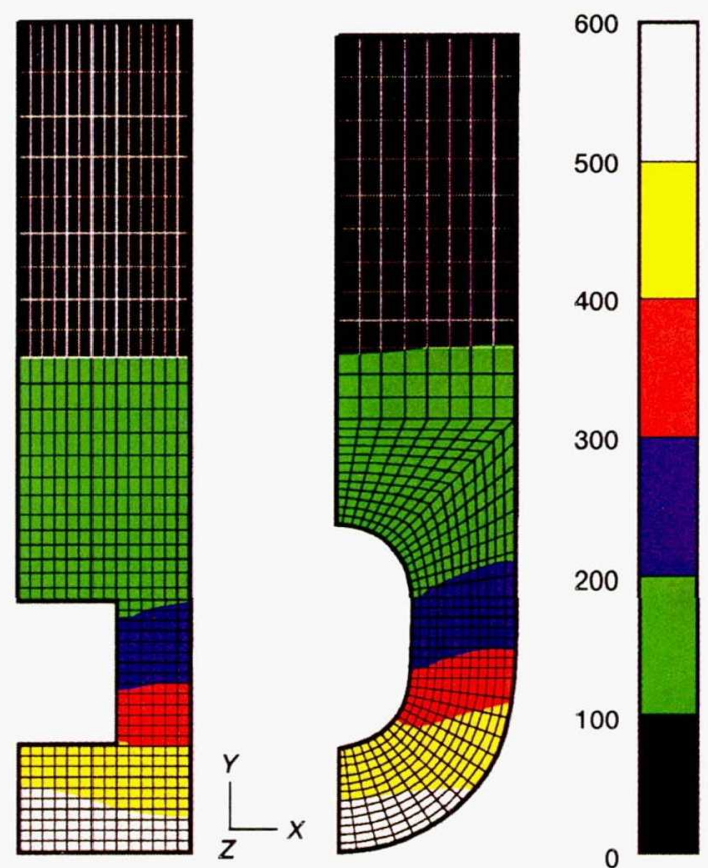

Figure 8.-Temperature distribution in rectangular and tubular channels during fifth cycle.

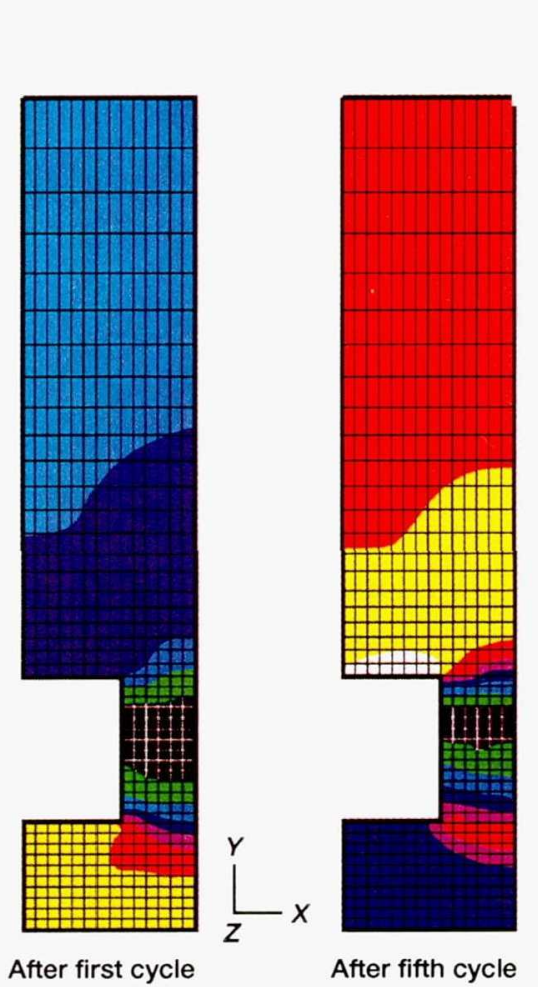

Stress,

$\mathrm{MPa}$

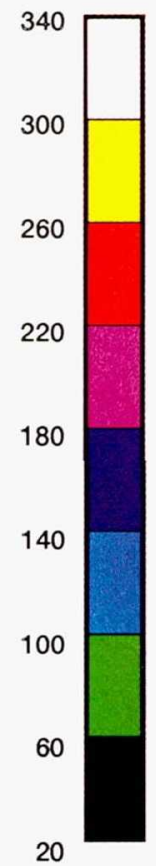

Figure 9.-Effective stress in rectangular channel after first and fifth cycles.
Pressure,

$\mathrm{MPa}$
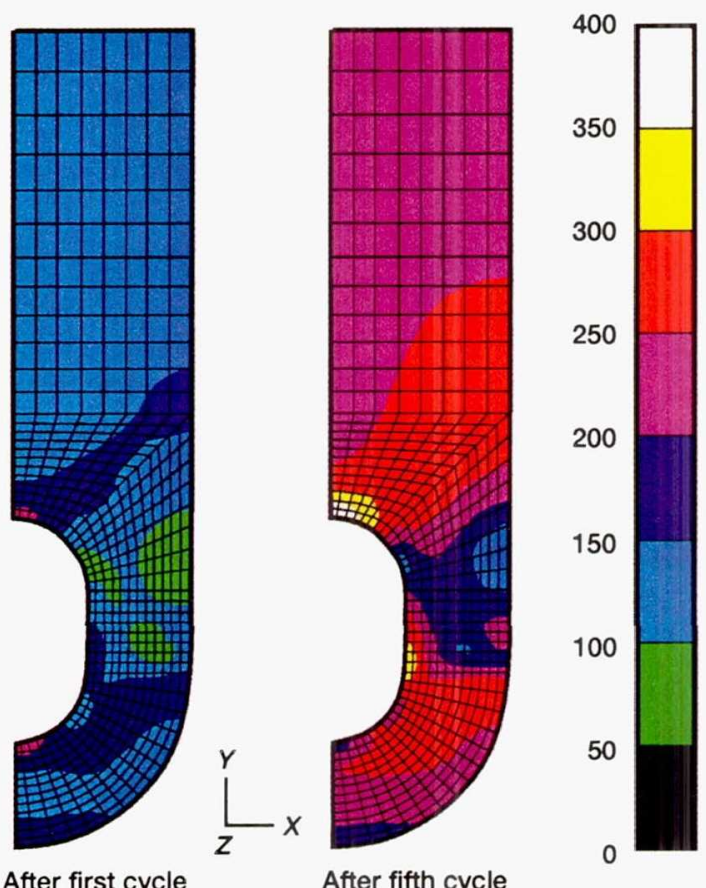

After first cycle

Figure 10.-Effective stress in tubular channel after first and fifth cycles.

Strain,

$\mathrm{mm} / \mathrm{mm}$
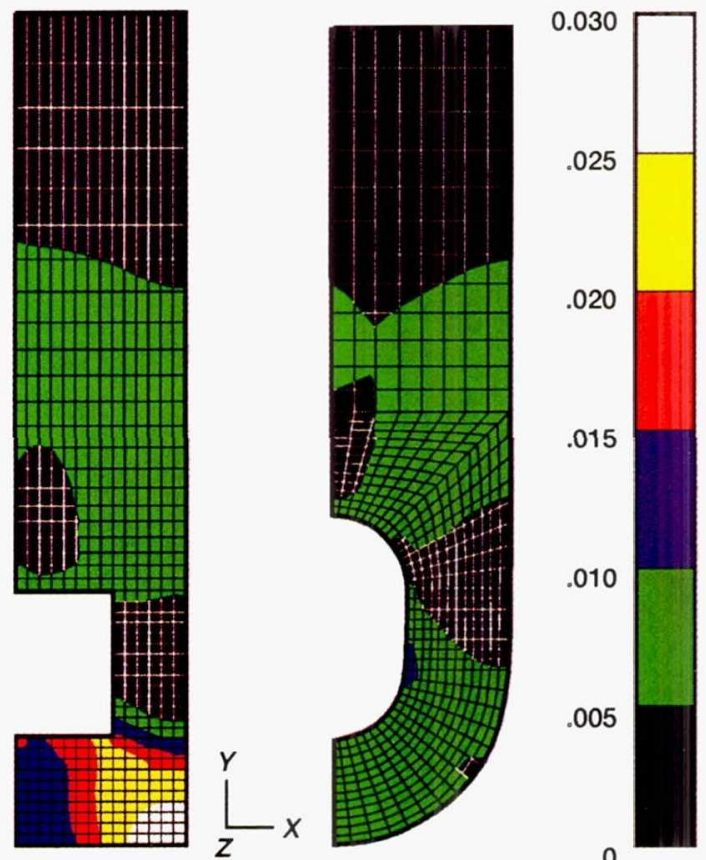

0

Figure 11.-Maximum effective strain in rectangular and tubular channels during fifth cycle. 
TABLE II.-CYCLIC TEMPERATURE AND PRESSURE LOADING HISTORIES

[From reference 10.]

\begin{tabular}{|c|c|c|}
\hline \multirow{2}{*}{} & \multicolumn{2}{|l|}{ Wall pressure, $\mathrm{kPa}(\mathrm{psia})$} \\
\cline { 2 - 3 } & Cold phase & Hot phase \\
\hline Hot-gas side & $96.5(14.0)$ & $2780(403)$ \\
Coolant side & $5100(740)$ & $6550(950)$ \\
\hline
\end{tabular}

ref. 10). The temperatures during the transient stage of the thermal cycle were obtained from corresponding steady-state temperatures by employing linear interpolation. The duration of a typical thermal-mechanical cycle was $3.5 \mathrm{sec}$. Timevarying nodal temperatures and elemental pressure loadings were applied to trace the loading cycle shown in figure 6 . The variations in material properties with temperature (see table I) were taken into consideration for these computations.

The effective stress ${ }^{1}$ distributions in the rectangular and tubular channels are shown in figures 9 and 10, respectively. These figures exhibit effective stress in the channels at the end of the first and fifth loading cycles. Examination of these figures reveals a significant redistribution of effective stress due to inelastic deformation. In the case of the rectangular channel, for example, at the end of the first cycle the effective stress in the lower part of the segment was higher than that in the upper part. But at the end of the fifth cycle, the effective stress in the lower part of the segment was lower than that in the upper part. Similar conclusions can be drawn for the tubular channels.

Figure 11 shows the maximum effective strains ${ }^{1}$ in the rectangular and tubular channels during the fifth loading cycle. The maximum effective strain in the tubular channel was considerably lower than that in the rectangular channel. Note also from this figure that the location of maximum effective strains differed for the rectangular and tubular channels.

The deformed shapes of the rectangular and tubular channels are plotted in figure 12 at the end of the fifth cycle. The deformations in the two channels are magnified by a factor of 1000 to facilitate visual interpretation. The figure shows a significantly larger deformation of the rectangular channel than of the tubular channel.

Figures 13 and 14 display the thinning of channel walls in the circumferential $(X)$ and radial $(Y)$ directions. The values plotted are at the ends of five loading cycles. The figures reveal that the rectangular channel wall thinned at a more rapid rate than did the tubular channel wall. For example, at the end of the fifth cycle the thickness of the rectangular channel wall had been reduced approximately twice as much as the tubular channel

\footnotetext{
${ }^{1}$ Effective stress : $\sigma_{e}=\frac{1}{\sqrt{2}}\left[\left(\sigma_{1}-\sigma_{2}\right)^{2}+\left(\sigma_{2}-\sigma_{3}\right)^{2}+\left(\sigma_{3}-\sigma_{1}\right)^{2}\right]^{1 / 2}$

Effective strain : $\varepsilon_{e}=\frac{1}{\sqrt{2}}\left[\left(\varepsilon_{1}-\varepsilon_{2}\right)^{2}+\left(\varepsilon_{2}-\varepsilon_{3}\right)^{2}+\left(\varepsilon_{3}-\varepsilon_{1}\right)^{2}\right]^{1 / 2}$
}

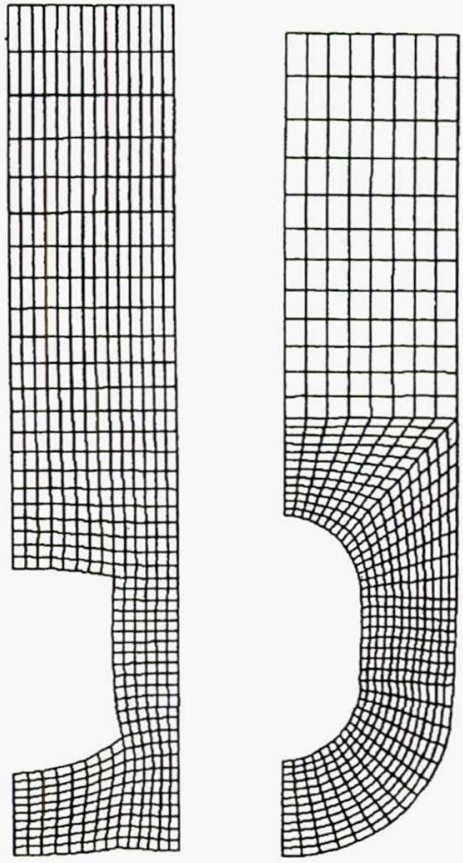

Figure 12.-Deformed shapes of rectangular and tubular channels after five cycles (magnification factor $=1000$ ).

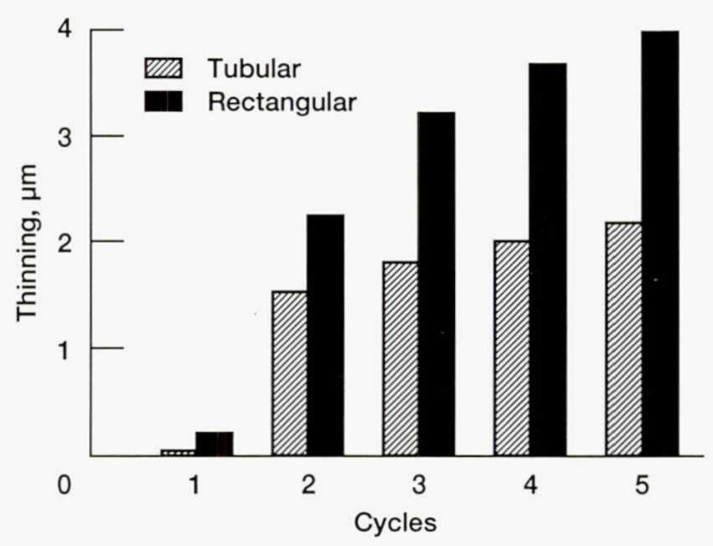

Figure 13.-Thinning in $X$-direction of rectangular and tubular channel walls after different numbers of cycles.

wall thickness. Looking at the deformed shapes in figure 12 the thinning in the radial direction is quite obvious.

It is clear from this discussion that for the same thermalmechanical loading cycles: (1) the deformation of the tubular channel was strikingly smaller than that of the rectangular channel and (2) the thinning of the tubular channel wall in the circumferential and radial directions was much slower than that of the rectangular channel wall. It may thus be concluded that using a tubular geometry for the coolant channel can greatly increase the durability and life of thrust chambers. 


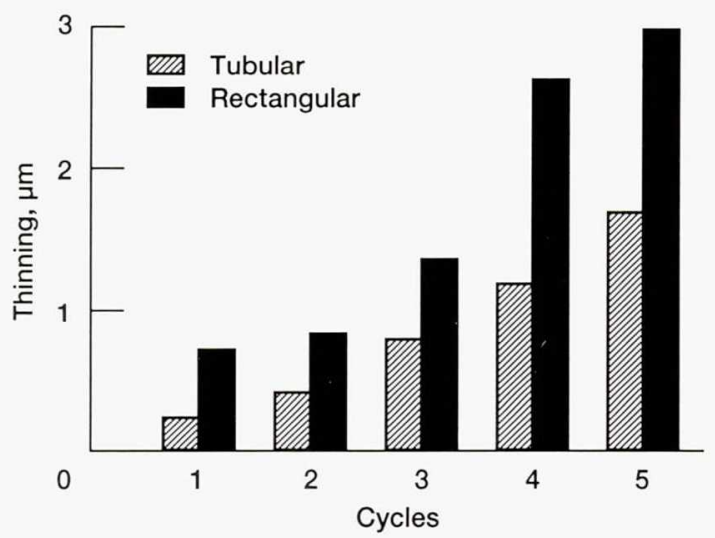

Figure 14.-Thinning in $Y$-direction of rectangular and tubular channel walls after different numbers of cycles.

\section{Life Analyses}

Life analyses of the rectangular and tubular channel combustion chambers were performed in accordance with an established procedure referred to as the "local strain" approach. The principal elements of this approach are

(1) Thermal and mechanical (pressure) mission loads imposed on the chamber

(2) Heat transfer coefficients for the fluids and the structural components

(3) Thermal conductivity and thermal expansion properties of the material

(4) Cyclic elastoplastic constitutive stress-strain-temperaturetime behavior of the material

(5) Low-cycle fatigue behavior of the material as represented by the cyclic effective plastic strainrange versus the cyclic crack initiation life

The first four elements are used as input to finite element analyses, which produce an output of local stresses, strains, and temperatures for each element as a function of mission operation time. Scanning the output locates the critical finite elements where temperature extremes and strainrange are largest and which hence are the most likely locations for thermal lowcycle fatigue cracks to initiate.

The material in the critical locale is deemed to have failed from fatigue crack initiation when a crack of critical size develops. The critical crack size is one large enough to cause fatigue separation of a uniaxial-loaded laboratory coupon subjected to an equivalent level of cyclic strain, temperature, and exposure time. No account is taken herein of cyclic propagation of cracks larger than this somewhat arbitrary critical initiation size. Low-cycle, strain-life fatigue curves for the copper material were approximated from data available for related thermal and temporal variations in cyclic conditions.

The thermal-mechanical loading cycle shown in figure 6 was applied repeatedly to both chamber designs. The maximum
TABLE III.-TEMPERATURES AND RANGES OF STRESS AND STRAIN AT CRITICAL LOCATIONS IN RECTANGULAR AND TUBULAR CHANNELS

\begin{tabular}{|c|c|c|c|c|c|}
\hline \multirow[t]{2}{*}{ Channel } & \multicolumn{2}{|c|}{$\begin{array}{l}\text { Metal temperature, } \\
{ }^{\circ} \mathrm{C}\left({ }^{\circ} \mathrm{F}\right)\end{array}$} & \multirow[t]{2}{*}{$\begin{array}{c}\text { Effective stress } \\
\text { range, } \\
\mathrm{MPa}(\mathrm{psi})\end{array}$} & \multicolumn{2}{|c|}{$\begin{array}{c}\text { Effective } \\
\text { strainrange, } \\
\text { percent }\end{array}$} \\
\hline & Max. & Min. & & Total & Plastic \\
\hline Rectangular & $538(1000)$ & $-218(-360)$ & $167(24$ 221) & 2.60 & 2.46 \\
\hline Tubular & 445 (833) & $-218(-360)$ & $210(30458)$ & 1.05 & .87 \\
\hline
\end{tabular}

and minimum temperatures, effective strains, and effective stresses at the most critical location for each chamber design are presented in table III. This information evolved from the thermal and structural analyses of the chambers as they were cycled between the temperature extremes of the mission loading cycle. Supplemental calculations indicated that the pressure loading, acting alone, would have a negligible effect on the deformation and life of the chambers, (i.e., the pressureinduced stresses were well below the yield strength of the material at the nominal maximum operating temperature of $\left.538^{\circ} \mathrm{C}\left(1000^{\circ} \mathrm{F}\right)\right)$. The associated creep rates also were small. Despite the small pressure influence when acting alone, the simultaneous application of the pressure loading and the thermal gradients gave rise to large cyclic strains and an accelerated rate of ratcheting. The thermal gradient (and associated thermal constraint) contribution to the range of total strain at the critical location was 2.6 percent for the rectangular channel design (of which 2.46 percentage points were plastic strain) and 1.05 percent for the tubular channel design (of which 0.87 percentage point was plastic strain). The time per cycle was extremely short $(3.5 \mathrm{sec})$, and only $2.3 \mathrm{sec}$ were spent at temperatures above the minimum cryogenic level. Consequently, during heating and cooling, the average strain rate was quite high (on the order of 1 to 2 percent per second). Because of the high strain rate, insufficient time was available for appreciable time-dependent, thermally activated creep deformation to occur. Any creep that might be present would occur most likely as stress relaxation during the brief, $0.8 \mathrm{sec}$, hold period at maximum temperature. Local stress relaxation of as much as 10 percent from the peak compressive stress would introduce a compressive creep strain of less than about 0.01 percent. This strain is approximately three orders of magnitude smaller than the plastic strainrange and would not be expected to affect the cyclic life of the channel wall. Consequently, for nominal chamber operation there was little concern for creepfatigue interaction during hot-fire testing of the chambers, and the life prediction analysis was simplified to a simple cyclic elastoplastic condition.

Pertinent high-temperature, low-cycle, plastic strain fatigue data have been reported by Conway et al. (ref. 11) for annealed OFHC copper at $538{ }^{\circ} \mathrm{C}\left(1000^{\circ} \mathrm{F}\right)$ in a nonoxidizing argon atmosphere. These data are shown in figure 15 as total effective 


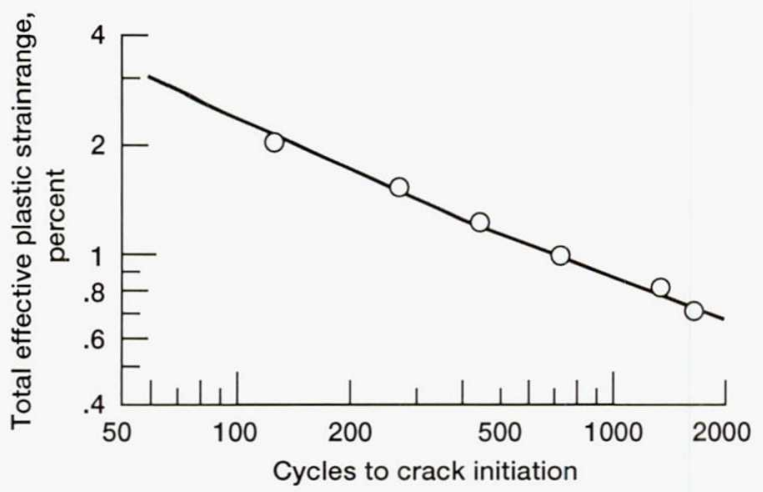

Figure 15.-Low-cycle fatigue resistance of OFHC copper at $538^{\circ} \mathrm{C}\left(1000^{\circ} \mathrm{F}\right)$ in argon at cyclic strain rate of 0.2 percent per second.

plastic strainrange versus cycles to crack initiation. The data had been generated at a cyclic strain rate of 0.2 percent per second, which is about one-tenth the rates experienced in the chambers. At this cyclic strain rate the extent of timedependent, thermally activated cyclic creep strain is negligible. Hence, the data meet an important criterion for applicability to the current analyses-negligible creep-fatigue interaction. Another important criterion for using Conway's isothermal data is their applicability to the variable temperatures experienced throughout the mission cycle of the combustion chambers. Because the tensile ductility of OFHC cooper is virtually insensitive to temperature, it is expected (ref. 12) that the lowcycle fatigue resistance (plastic strainrange versus life) would also be insensitive to temperature. Tensile test reduction of area varies from 81 to 98 percent over the temperature range of concern (approximately -218 to $538^{\circ} \mathrm{C} ;-360$ to $1000^{\circ} \mathrm{F}$ ). If the fatigue failure relation is independent of temperature, and only one deformation mechanism is present (cyclic plasticity), it is reasonable to assume that the fatigue failure relation will be directly applicable to the thermal cycling conditions being considered. In other words, one curve, determined at any isothermal temperature within the cyclic range of -218 to $538^{\circ} \mathrm{C}\left(-360\right.$ to $\left.1000^{\circ} \mathrm{F}\right)$ should be applicable to all temperatures within the range if the strains in the cycle are predominately plastic. The latter was the case for both the isothermal fatigue test data and the strains occurring at the critical locations within the chambers. Note that environmental oxidation interaction was precluded by use of an inert argon atmosphere for coupon testing and by the hydrogen-rich, reducing atmosphere present during chamber testing. Note also that OFHC copper is not embrittled by the presence of hydrogen (ref. 13).

For temperatures far above $538^{\circ} \mathrm{C}\left(1000^{\circ} \mathrm{F}\right)$, however, creep and associated creep damage cannot be ignored because they increase with temperature at an exponential rate. Some of the chamber tests experienced temperatures as high as $671{ }^{\circ} \mathrm{C}$ $\left(1240^{\circ} \mathrm{F}\right)$; therefore, creep strain due to the internal channel pressure acting alone would become (based on a simple LarsonMiller parameter calculation) nearly three orders of magnitude greater than at $538^{\circ} \mathrm{C}\left(1000{ }^{\circ} \mathrm{F}\right)$. Consequently, the timedependent deformation would become a nonnegligible fraction of the plastic strain with a resultant loss in cyclic life expectancy. Quantitatively acceptable calculations of the creep-strain contributions were not possible without performing threedimensional finite element viscoplasticity analyses for the highest temperature chamber tests. Qualitatively, a large decrease (approaching an order of magnitude in life) in cyclic durability could be expected.

Predicting fatigue crack initiation life for the tubular and rectangular chamber designs under nominal thermal and mechanical loading conditions is a rather simple task. The two equivalent plastic strainranges of 2.46 and 0.87 percent were entered into the Manson-Coffin law shown in figure 15, and the respective cyclic lifes of 70 to 750 cycles to failure were determined. The greater fatigue life of the tubular relative to the rectangular channel design is significant. A more than tenfold improvement in predicted low-cycle fatigue life is due directly to the reduction of the thermally induced strainrange in the tubular channel design.

\section{Discussion}

This effort showed that the strain levels for the tubular channel were significantly lower than those for the rectangular channel. Strainrange was used to predict a significant increase in mission life. The analyses predicted a reduction in strainrange from 2.6 percent in the rectangular channel to 1.05 percent in the tubular channel. Such a dramatic reduction in strainrange was expected to provide a tenfold increase in life by "the local strain approach." The test results, however, only showed a twoto threefold increase in life.

Both analyses and tests showed that significant improvements in life can be achieved by accommodating strain instead of resisting it, but the amounts of improvement differed. This difference was principally the result of our inability to accurately include all effects of the real environment. Because of this reality, only relative comparisons could be made. The difference in life indicated by the analyses and the tests was due primarily to two reasons.

First, a fatigue analysis was performed to estimate the lives of the tubular and rectangular channel designs. Thermalmechanical ratcheting, not fatigue, is the failure mode of these types of chambers. But both fatigue and thermal-mechanical ratcheting are dominated by the magnitude of the strainrange. Therefore, it is reasonable to assume that a fatigue analysis would provide a good, but not exact, indicator of relative life improvement.

Second, there was a difference in operating versus assumed temperatures. The analyses used a maximum wall temperature of $538^{\circ} \mathrm{C}\left(1000^{\circ} \mathrm{F}\right)$ for both chamber configurations so that a direct comparison could be made. In testing the two configurations it was difficult to achieve an exact temperature of 
$538^{\circ} \mathrm{C}\left(1000^{\circ} \mathrm{F}\right)$. The tubular channel was run slightly hotter than the analysis temperature (on the order of $571^{\circ} \mathrm{C}\left(1060^{\circ} \mathrm{F}\right)$ ). Consequently, some of the potential improvement in durability because of a more compliant geometry was offset by a higher temperature with attendant higher rates of damage due to the probable introduction of cyclic creep strain. Furthermore, because of the nominally higher temperature of the tubular channel, greater surface roughening was observed. This phenomenon, known as blanching (ref. 14), escalated the tubular wall temperature to an estimated value of $830^{\circ} \mathrm{C}\left(1525^{\circ} \mathrm{F}\right)$ at the time testing was suspended. This additional increase in temperature of the tubular channel chamber reduced its life even further relative to both the tubular channel analysis and the experimental results of the rectangular channel chamber.

It is obvious from the results of both the testing and analyses that a tubular channel geometry reduces the strainrange and therefore increases the life of a rocket thrust chamber.

\section{Conclusions}

Presently, advanced hydrogen-oxygen rocket combustion chambers have a limited life due to thermal-mechanical fatigue and ratcheting. This ratcheting is a strong function of the material strength and the strainrange. In the past numerous attempts have been made to extend the useful life of rocket combustion chambers by improving the chamber material strength. These efforts resulted in little life improvement because the strain levels at the high heat fluxes present in rocket combustion chambers are in the range 2 to 4 percent. This level of strain is roughly an order of magnitude greater than the yield strain of copper or copper alloys.

The work herein takes steps to dramatically improve combustion chamber life by reducing the strainrange the material experiences. This reduction is accomplished by modifying the geometry of the hot-gas-side surface of the combustion chamber. The tubular geometry reduces the compressive strain, thus reducing the total strainrange and extending life.

The viscoplastic analysis, durability analysis, and test results reported herein verified that the more compliant tubular construction extends the life of the combustion chamber. The viscoplastic analysis found that the total strainrange of the tubular channel was reduced to 1.05 percent from 2.6 percent in the rectangular channel. The durability analysis found that the reduction in strainrange could extend the life of the combustion chamber by as much as 1000 percent. The test results found that the compliant chamber extends life by 300 percent.

\section{Appendix-Viscoplastic Model}

The viscoplastic model put forth by Freed and Verrilli (ref. 3) and used in the present work incorporates two internal state variables - tensorial backstress $B_{i j}$ and a scalar drag stress
$D$. The kinematic, or flow-induced, anisotropic hardening is accounted for by the backstress $B_{i j}$, and the isotropic hardening is incorporated through the drag stress $D$. There is no yield surface in the model. The assumption of uncoupled dynamic and static recovery terms provides a simpler mathematical structure to the model.

The total strain rate $\varepsilon_{i j}$ is assumed to be the sum of elastic $\dot{\varepsilon}_{i j}^{\text {el }}$, inelastic $\dot{\varepsilon}_{i j}^{\text {in }}$, and thermal $\dot{\varepsilon}_{i j}^{\text {th }}$ strain rate components. This can be written as

$$
\dot{\varepsilon}_{i j}=\dot{\varepsilon}_{i j}^{\mathrm{el}}+\dot{\varepsilon}_{i j}^{\text {in }}+\dot{\varepsilon}_{i j}^{\text {th }} \quad(i, j=1,2,3)
$$

Here $\varepsilon$ denotes strain and a dot over a symbol indicates its derivative with respect to time $t$. Note that the inelastic strain in a viscoplastic formulation includes plasticity, creep, relaxation, etc., and their interactions.

The material is assumed to be isotropic, and Hooke's law is used to relate the stress rate $\sigma_{i j}$ to the elastic strain rate $\dot{\varepsilon}_{i j}^{\text {el }}$, that is,

$$
\dot{\varepsilon}_{i j}^{\mathrm{el}}=\frac{1+v}{E} \dot{\sigma}_{i j}-\frac{v}{E} \dot{\sigma}_{k k} \delta_{i j}
$$

In the preceding equation, $E$ is Young's modulus, $v$ is Poisson's ratio, and $\delta_{i j}$ is the Kronecker delta. Following the usual summation convention, the repeated subscripts in the preceding equation and elsewhere imply summation.

We define deviatoric stress $S_{i j}$ as

$$
S_{i j}=\sigma_{i j}-\frac{1}{3} \sigma_{k k} \delta_{i j}
$$

Denoting the backstress as $B_{i j}$, the effective stress $\Sigma_{i j}$ is defined as

$$
\Sigma_{i j}=S_{i j}-B_{i j}
$$

The second variant of effective stress $J_{2}$ is

$$
J_{2}=\frac{1}{2} \Sigma_{i j} \Sigma_{i j}
$$

and the function $F$ is defined by

$$
F=\frac{J_{2}}{D}
$$

where $D$ is the drag stress.

The constitutive equations of the model now follow. We first define the thermal diffusivity function $\theta$, which contains the temperature dependence of the model. It is given by

$$
\theta= \begin{cases}\exp \left(-\frac{Q}{k T}\right) \quad T \geq 0.5 T_{m} & \\ \exp \left\{-\frac{2 Q}{k T_{m}}\left[\ln \left(\frac{T_{m}}{2 T}\right)+1\right]\right\} & T \leq 0.5 T_{m}\end{cases}
$$


in which $K$ is the Boltzmann constant, $Q$ is the activation energy, $T$ is the absolute temperature, and $T_{m}$ is the melting point of the material.

The function $Z$, called the Zener-Hollomon parameter, has the following expressions:

$$
Z=\left\{\begin{array}{l}
A F^{n} \quad F \leq 1 \\
A \exp [n(F-1)] \quad F \geq 1
\end{array}\right.
$$

The flow law is now given by

$$
\dot{\varepsilon}_{i j}=\theta Z \frac{\Sigma_{i j}}{J_{2}}
$$

The differential equations governing the growth of the internal state variables $B_{i j}$ and $D$ are

$$
\dot{B}_{i j}=H\left(\dot{\varepsilon}_{i j}^{\text {in }}-\frac{B_{i j}}{L} I_{2}\right)
$$

and

$$
\dot{D}=h\left[\frac{I_{2}}{G}-\theta r(G)\right]
$$

where

$$
I_{2}=\theta Z
$$

In the above equations $H, L$, and $h$ are inelastic material constants. The constant $L$ denotes the limiting value of the backstress at kinematic saturation (ref. 3).

The following expressions then define the recovery function $r$ :

$$
\begin{aligned}
& r(G)=\left\{\begin{array}{lr}
0 & D=D_{o} \\
R(G) & D>D_{o}
\end{array}\right. \\
& R(G)=\left\{\begin{array}{l}
A G^{n-1} \quad G \leq 1 \\
A \exp [n(G-1)] / G
\end{array} \quad G \geq 1\right.
\end{aligned}
$$

and

$$
G=\frac{L}{S-D}
$$

where $S$ and $D_{o}$ are material constants.
The function $r$ is constrained by the following dissipativity condition:

$$
r \geq Z\left[\frac{1}{G}-2\left(F+\frac{B_{2}^{2}}{L D}\right)\right]
$$

where

$$
B_{2}=\frac{1}{2} B_{i j} B_{i j}
$$

This condition must be satisfied for the theory to be thermodynamically admissible. The material constants for this model characterized for copper are listed in table I.

\section{References}

1. Quentmeyer, R.J.: Experimental Fatigue Life Investigation of Cylindrical Thrust Chambers. NASA TM X-73665, 1977.

2. Kazaroff, J.M.; Jankovsky, R.J.; and Pavli, A.J.: Hot Fire Test Results of Subscale Tubular Combustion Chambers. NASA TP-3222, 1992.

3. Freed, A.D.; and Verrilli, M.J.: A Viscoplastic Theory Applied to Copper. NASA TM-100831, 1988.

4. Arya, V.K.; and Kaufman, A.: Finite Element Implementation of Robinson's Viscoplastic Model and Its Application to Some Uniaxial and Multiaxial Problems. J. Eng. Comput., vol. 6, no. 3, 1989, pp. 537-547.

5. MARC General Purpose Finite Element Program. MARC Research Analysis Corporation, Palo Alto, CA, 1988

6. Arya, V.K.; Hornberger, K.; and Stamm, H.: On the Numerical Integration of Viscoplastic Models. Report No. 4082, Kernforschungszentrum, Karlsruhe, Germany, 1986.

7. Arya, V.K.: Analytical and Finite Element Solutions of Some Problems Using a Viscoplastic Model. J. Comput. Struct, vol. 33, no. 4, 1989, pp. 957-967.

8. Arya, V.K.: Finite Element Analysis of Structural Components by Using Viscoplastic Models With Application to a Cowl Lip Problem. J. Mater. High Temp., vol. 9, no. 4, 1991, pp. 201-208

9. PATRAN II User Manual. PDA Engineering, Santa Ana, CA, 1984.

10. Armstrong, W.H.: Structural Analysis of Cylindrical Thrust ChambersFinal Report, Vol. 1. (LMSC-HREC-TR-D568827-VOL-1, Lockheed Missiles and Space Co., NASA Contract NAS3-21361) NASA CR-159522, 1979.

11. Conway, J.B.; Stentz, R.H.; and Berling, J.T.: High Temperature, LowCycle Fatigue of Copper-Base Alloys in Argon; Part I-Preliminary Results for 12 Alloys at $1000^{\circ} \mathrm{F}\left(538^{\circ} \mathrm{C}\right)$. NASA CR-121259, 1973.

12. Halford, G.R.; Hirschberg, M.H.; and Manson, S.S: Temperature Effects on the Strainrange Partitioning Approach for Creep Fatigue Analysis. Fatigue at Elevated Temperatures, ASTM STP-520, American Society for Testing and Materials, 1973, pp. 658-669.

13. Metals Handbook Eighth ed. Vol. 1. American Society for Metals, Novelty, OH, 1961, p. 996.

14. Morgan, D.B.; and Franklin, J.E.: Hot-Fire Test Investigation of Copper Combustion Chamber Blanching. The 1989 JANNAFPropulsion Meeting, D.S. Eggleston and K.L. Strange, eds., CPIA Publication 515, vol. 3, 1989, pp. 417-426. 
Public reporting burden for this collection of information is estimated to average 1 hour per response, including the time for reviewing instructions, searching existing data sources, gathering and maintaining the data needed, and completing and reviewing the collection of information. Send comments regarding this burden estimate or any other aspect of this collection of information, including suggestions for reducing this burden, to Washington Headquarters Services, Directorate for Information Operations and Reports, 1215 Jefferson Davis Highway, Suite 1204, Arlington, VA 22202-4302, and to the Office of Management and Budget, Paperwork Reduction Project (0704-0188), Washington, DC 20503.

\begin{tabular}{|l|l|l|}
\hline 1. AGENCY USE ONLY(Leaveblank) & $\begin{array}{r}\text { 2. REPORTDATE } \\
\text { March } 1994\end{array}$ & $\begin{array}{r}\text { 3. REPORT TYPE AND DATES COVERED } \\
\text { Technical Paper }\end{array}$ \\
\hline
\end{tabular}

4. TITLE AND SUBTITLE

5. FUNDING NUMBERS

Structurally Compliant Rocket Engine Combustion Chamber-Experimental and Analytical Validation

\section{AUTHOR(S)}

WU-584-04-11

Robert S. Jankovsky, Vinod K. Arya, John M. Kazaroff, and Gary R. Halford

\section{PERFORMING ORGANIZATION NAME(S) AND ADDRESS(ES)}

National Aeronautics and Space Administration

Lewis Research Center

Cleveland, Ohio 44135-3191
8. PERFORMING ORGANIZATION REPORT NUMBER

E-8261

9. SPONSORING/MONITORING AGENCY NAME(S) AND ADDRESS(ES)

10. SPONSORING/MONITORING AGENCY REPORT NUMBER

National Aeronautics and Space Administration

Washington, D.C. 20546-0001

NASA TP-3431

\section{SUPPLEMENTARY NOTES}

Portions of this material were presented at the 1993 JANNAF Propulsion Meeting, Monterey, California, November 15-18, 1993. Robert S. Jankovsky, John M. Kazaroff, and Gary R. Halford, NASA Lewis Research Center; Vinod K. Arya, University of Toledo, Toledo, Ohio 43606. Responsible person, Robert S. Jankovsky, organization code 5320, (216) 433-7515.

12a. DISTRIBUTION/AVAILABILITY STATEMENT 12b. DISTRIBUTIONCODE

Unclassified - Unlimited

Subject Categories 20 and 39

\section{ABSTRACT (Maximum 200 words)}

A new, structurally compliant rocket engine combustion chamber design has been validated through analysis and experiment. Subscale, tubular channel chambers have been cyclically tested and analytically evaluated. Cyclic lives were determined to have a potential for 1000 percent increase over those of rectangular channel designs, the current state of the art. Greater structural compliance in the circumferential direction gave rise to lower thermal strains during hot firing, resulting in lower thermal strain ratcheting and longer predicted fatigue lives. Thermal, structural, and durability analyses of the combustion chamber design, involving cyclic temperatures, strains, and low-cycle fatigue lives, have corroborated the experimental observations.

14. SUBJECT TERMS

Combustion chamber; Fatigue; Tubular channel

16. PRICECODE

$\mathrm{A} 03$

17. SECURITY CLASSIFICATION OFREPORT

Unclassified
18. SECURITY CLASSIFICATION OF THIS PAGE

Unclassified
19. SECURITY CLASSIFICATION OF ABSTRACT Unclassified 

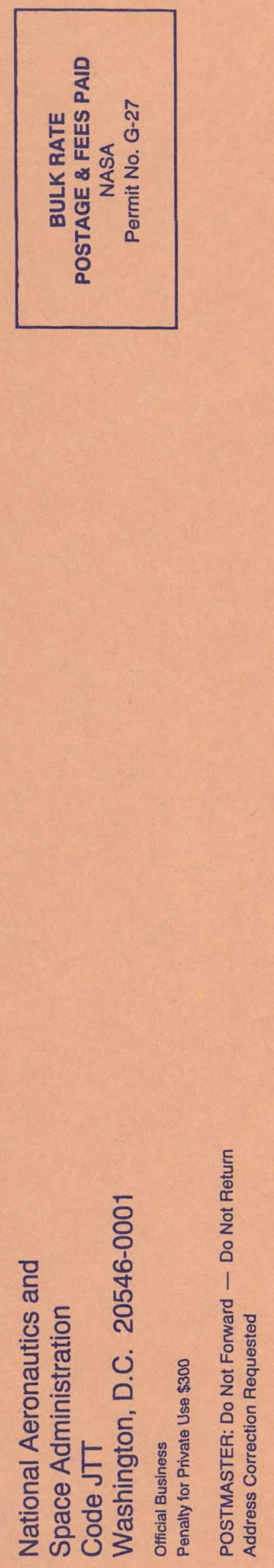